\title{
Overview of Stirling Technology Research at NASA Glenn Research Center
}

\author{
Scott D. Wilson ${ }^{1}$, Nicholas A. Schifer ${ }^{2}$, Zachary D. Williams ${ }^{3}$, and Jonathan F. Metscher ${ }^{4}$ \\ NASA Glenn Research Center, Cleveland, Ohio, 44135
}

\begin{abstract}
Stirling Radioisotope Power Systems (RPS) are under development to provide power on future space science missions where robotic spacecraft will orbit, flyby, land or rove using less than a quarter of the plutonium the currently available RPS uses to produce about the same power. Glenn Research Center's (GRC's) newly formulated Stirling Cycle Technology Development Project (SCTDP) continues development of Stirling-based systems and subsystems, which include a flight-like generator and related housing assembly, controller, and convertors. The project also develops less mature technologies under Stirling Technology Research, with a focus on demonstration in representative environments to increase the technology readiness level (TRL). Matured technologies are evaluated for selection in future generator designs. Stirling Technology Research tasks focus on a wide variety of objectives, including increasing temperature capability to enable new environments, reducing generator mass and/or size, improving reliability or system fault tolerance, and developing alternative designs. The task objectives and status are summarized.
\end{abstract}

$\begin{array}{ll} & \\ A C T & =\text { Advanced Cooling Technologies } \\ A C U & =\text { ASC Controller Unit } \\ \text { ASC }(-E) & =\text { Advanced Stirling Convertor (Engineering design \#1) } \\ (-E 2) & =\text { Engineering design \#2 } \\ (-E 3) & =\text { Engineering design } \# 3 \\ (E U 2) & =\text { Engineering Unit design } \# 2 \\ (-F) & =\text { Fight design } \\ \text { ASRG } & =\text { Advanced Stirling Radioisotope Generator } \\ C O N O P S & =\text { Concept of Operations } \\ D C C & =\text { Dual Convertor Controller } \\ D O E & =\text { Department of Energy } \\ F L D T & =\text { Fast Linear Displacement Transducer } \\ G H A & =\text { Generator Housing Assembly } \\ G R C & =\text { Glenn Research Center } \\ H T L A & =\text { High-Temperature Linear Alternator } \\ \text { LMSSC } & =\text { Lockheed Martin Space Systems Company } \\ M L I & =\text { Multi-Layer Insulation } \\ R C H S & =\text { Radial Core Heat Spreader } \\ R P S & =\text { Radioisotope Power Systems } \\ S C T D P & =\text { Stirling Cycle Technology Development Project } \\ \text { SRG-110 } & =\text { Stirling Radioisotope Generator 110 watt } \\ T D C & =\text { Technology Demsonstation Convertor } \\ T R L & =\text { Technology Readiness Level } \\ V C H P & =\text { Variable Conductance Heat Pipe } \\ & \end{array}$

${ }^{1}$ Mechanical Engineer, Thermal Energy Conversion Branch, 21000 Brookpark Rd/Mail Stop 301-2, AIAA Member.

${ }^{2}$ Mechanical Engineer, Thermal Energy Conversion Branch, 21000 Brookpark Rd/Mail Stop 301-2, AIAA Member.

${ }^{3}$ Mechanical Engineer, Thermal Energy Conversion Branch, 21000 Brookpark Rd/Mail Stop 301-2, AIAA Member.

${ }^{4}$ Mechanical Engineer, Thermal Energy Conversion Branch, 21000 Brookpark Rd/Mail Stop 301-2, AIAA Member.

American Institute of Aeronautics and Astronautics 


\section{Introduction}

Stirling Radioisotope Power Systems (RPS) are under development to provide power on future space science missions where robotic spacecraft will orbit, flyby, land or rove. NASA Glenn Research Center (GRC) supported development of a high-efficiency Stirling Radioisotope Generator for potential space missions from 1999 to 2006 under SRG-110, designed to use one fourth of the nuclear fuel required on heratige thermoelectrics.

The Department of Energy (DOE) selected Lockheed Martin Space Systems Company (LMSSC) as the System Integration Contractor and the generator design housed two Infinia Stirling convertors, called Technology Demsonstation Convertors (TDCs). The project was redirected in 2006 to make use of a more efficient and lower mass Advanced Stirling Convertor (ASC) that was being developed by Sunpower, Inc. under contract to GRC. ${ }^{1}$ The DOE managed a flight contract with LMSSC and subcontractor Sunpower Inc. from 2007 to 2013 to build Advanced Stirling Radioisotope Generators (ASRGs), with support from NASA GRC. Sunpower Inc. held two parallel contracts to produce Advanced Stirling Convertors (ASCs), one with Lockheed Martin to produce ASC-F flight units, and one with GRC for the production of ASC-E3 engineering unit "pathfinders" that are built to the flight design. ${ }^{2}$ DOE initiated termination of that contract in late 2013, primarily due to budget constraints. Before the ASRG flight development project ended, significant progress was made developing the generator design and enable system level testing. In 2014, NASA GRC completed the build and assembly of the ASRG Engineering Unit design \#2 (EU2). ${ }^{3}$ The ASRG EU2 consists of the first pair of ASC-E3 convertors, Lockheed Martin's Engineering Development Unit (EDU) 4 controller, and an aluminum housing. The electrically-heated system characterization included measurement of convertor, controller, and generator performance and efficiency, quantification of control authority of the controller, disturbance force measurement with varying piston phase and piston amplitude, and effect of spacecraft DC bus voltage variation on EU2 performance. The test results provides a basic understanding of EU2 characteristics that can be evaluated relative to system requirements and predictions. $^{4}$

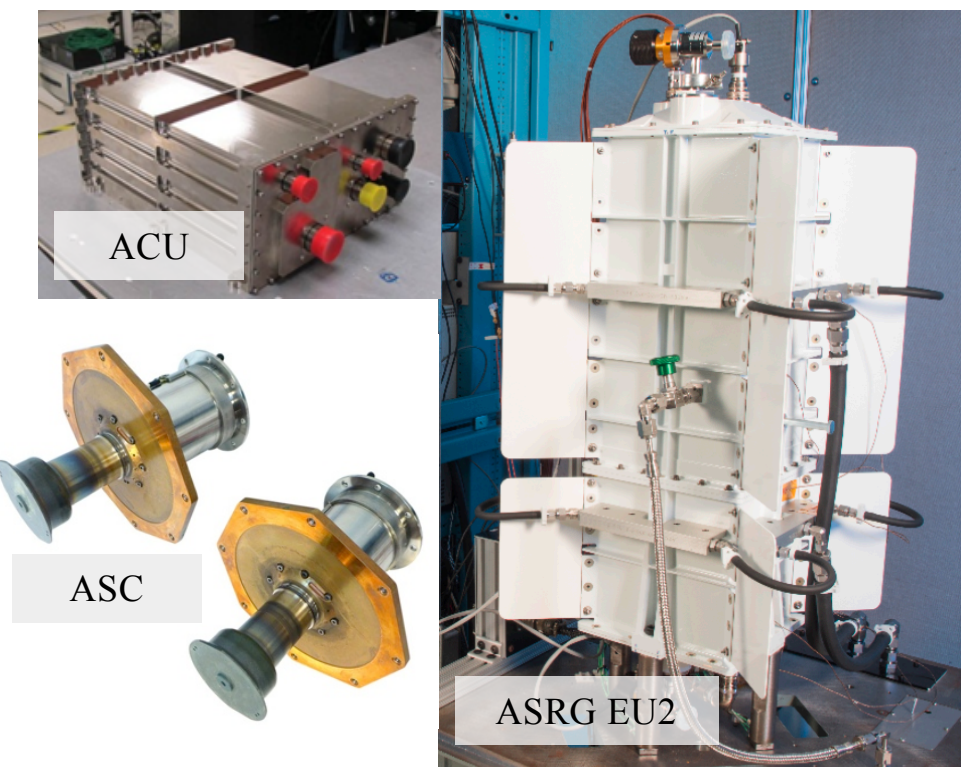

Figure 1. ASRG EU2 and ASC and ACU Subassemblies.

Prior to integration into higher level system tests, convertors are tested to enable independent performance verification, provide a way to simulate the life cycle of a flight convertor within certain limits, and mitigate risk by providing the life certification plan with input data. To start, each completed ASC convertor undergoes Final Performance Testing at the vendor before entering the hardware acceptance review. After approval, the convertors are delivered to GRC for additional testing. Upon receipt, the ASC undergoes inspection, characterization, and performance verification. The specified operating points were designed to simulate reference mission conditions, such as at the beginning and end of a mission, when the amount of available heat varies due to the natural decay of the radioisotope heat source. ${ }^{5}$ Different configurations simulate various scenarios throughout the life of a flight convertor. Horizontal operation simulates ground integration prior to fueling, random vibration testing simulates launch conditions, and vertical operation simulates a cruise phase. Convertors can accumulate several thousand hours before entering what is considered to be the random failure phase of life, where failures count against life certification. ASCs have been on test at GRC since earlier prototypes were received in 2007, accumulating over 385,000 hours of operation.

Radioisotope Power System (RPS) Stirling development was reformulated in FY2015 and being worked under the Stirling Cycle Technology Development Project (SCTDP). The SCTDP will continue to develop systems as well as focused on maturing technologies by demonstration in higher fidelity systems and representative environments to increase the technology readiness level. Matured technologies will be evaluated for selection in future generator designs. Stirling Technology Research area tasks focus on a wide variety of objectives, including increasing 
performance and/or expanding mission space, reducing mass and/or size, improving reliability or system fault tolerance, and developing alternative designs.

\section{Increasing Performance and/or Expanding Mission Space}

The ASC-E3 design is required to operate at a maximum alternator housing exterior surface temperature of 130 ${ }^{\circ} \mathrm{C}$, which ensures the alternator magnets are not demagnetized. The organics used in the construction of the alternator have a 30 to $35{ }^{\circ} \mathrm{C}$ margin over the requirement. While that design is able to support many relevant mission environments, an increased temperature capability could significantly simply concept of operations (CONOPS) for a Venus flyby, lunar or Mars surface equatorial missions, or other environments that exceed the current capability. Recent efforts have been aimed at increasing the alternator temperature limit by 50 to $70{ }^{\circ} \mathrm{C}$, including high temperature characterization of magnets and organic materials. Regarding evaluation of organics, initial screening tests of epoxy pastes were performed to enable down selection of a single epoxy for use in a hightemperature linear alternator test rig, described in the next section. Initial candidates were screened and the Henkel Hysol EA9394C-2 epoxy paste was selected, based on limited data.

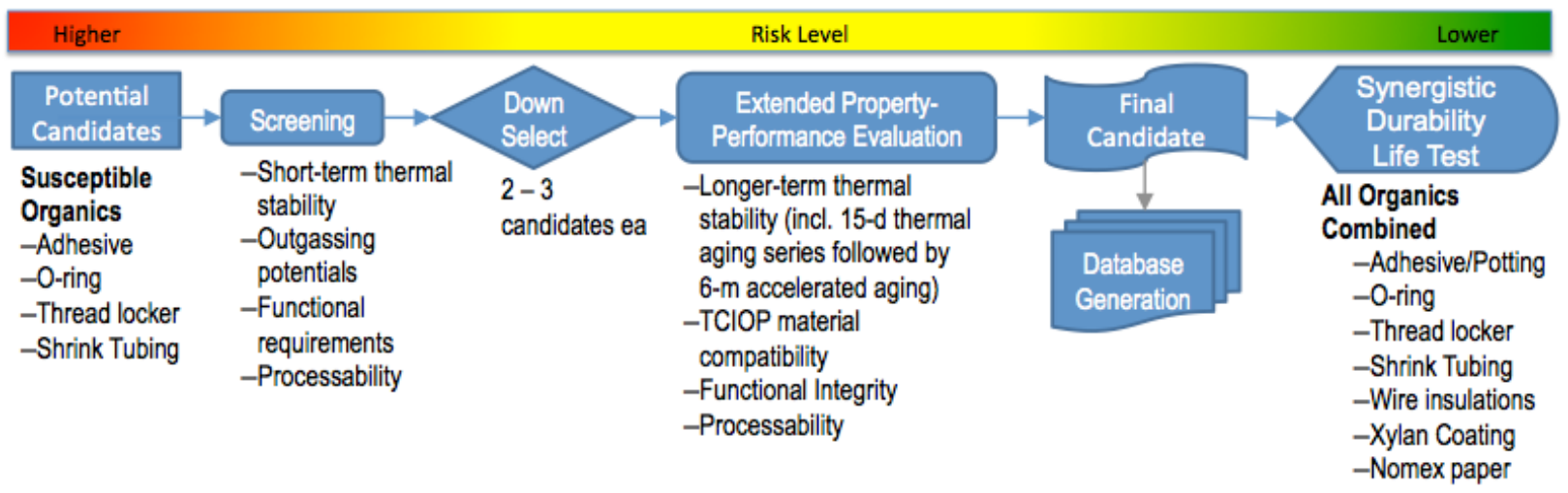

Figure 2. Nominal Test Campaign for Evaluation of Organics. TCIOP: Temperature-alone Combined Insitu Outgassing test w/ Pre-mix ASC outgas.

The nominal test campaign for evaluation of organics is shown in Figure 2. In screening tests, the two best candidates were screened from several commercial candidates identified and evaluated for processability, short-term thermal stability, outgassing potential, and magnet bonding integrity. After the epoxy was selected for use in the high-temperature alternator test rig, the two candidate systems, Henkel Hysol EA9394C-2 epoxy paste and 3M AF131-2 supported film epoxy adhesive, were then more extensively evaluated for longer-term thermal stability, functionality, and material compatibility using various thermal and accelerated thermal aging tests for up to six months, involving comprehensive and systematic residual property characterizations. Critical functions for the optimum high-temperature ASC adhesive include long term thermal stability, handlability, processability at lower cure temperatures, low outgassing, durability and radiation hardness.

Based on extended property performance evaluation results, the recommendation was to continue using the Hysol EA9394C-2, which showed more stable bonding properties with aging time at all three aging temperatures up to $250{ }^{\circ} \mathrm{C}$. Those results suggest the Hysol EA9394C-2 has better longer-term thermal stability than the AF131-2, which suffered significant property degradation when aged above $200^{\circ} \mathrm{C}$ due to thermal degradation of material. Additionally, EA9394C-2 showed significant strength drops at $200{ }^{\circ} \mathrm{C}$, greater than those of the AF131-2 in most cases. However, the drop resulted from temperature capability of the material in terms of network status, such as $\mathrm{T}_{\mathrm{g}}$, and adhesion mechanisms, not necessarily involving thermal degradation. The results suggest that bonding properties of the EA9394C-2 epoxy were not majorly affected by aging time for all aging temperatures up to $225^{\circ} \mathrm{C}$.

\section{A. High-Temperature Alternator Demonstration}

High-level objectives for testing the high-temperature linear alternator include demonstrating functionality at temperatures above $160{ }^{\circ} \mathrm{C}$, characterizing alternator performance at $200^{\circ} \mathrm{C}$, and identifying degradation modes for material used in the construction of the alternator during extended exposures at $200^{\circ} \mathrm{C}$. The high-temperature linear alternator (HTLA) design was developed by Sunpower, Inc. and GRC. The ASC design has limited temperature 
capability due to the magnet type $(\mathrm{NdFeB})$ and the epoxy used to bond the magnets to the ASC magnet can. The HTLA has been modified to use NEOMAX N32EZ magnets, as well as a higher temperature Hysol EA9394C-2 epoxy to increase temperature capability. The N32EZ magnets have increased temperature range of up to $200^{\circ} \mathrm{C}$, among the highest for $\mathrm{NdFeB}$ magnets.

The HTLA is coupled to a DTR0101 linear alternator dynamometer, which serves as the drive motor for the experiment and is powered by a Chroma programmable AC source. The HTLA and drive motor are coupled together through a flex rod and Kistler load cell, which measures the dynamic force on the drive shaft. The displacement of the shaft is measured by a fast linear displacement transducer (FLDT) mounted underneath the dynamometer. Electric power output from the HTLA is connected through a Yokogawa power meter to the resistive load, as well as, a capacitor bank for power factor correction. The Chroma AC power source that powers the drive motor is set to the design frequency of the HTLA, at $102 \mathrm{~Hz}$. The power output of the LA is designed to be 80 We with a mover amplitude of $4.5 \mathrm{~mm}$. The HTLA is insulated using Cotronics ceramic paper and heated using two DC-powered electric heater bands along the inner and outer iron stators to achieve desired test temperatures. A series of thermocouples measure the temperature around the inside and outside of the alternator. The HTLA and dynamometer are enclosed in a containment vessel that is pressurized with helium to $10 \mathrm{psig}$. The enclosed system is secured to a large steel block on springs to reduce vibration of the test rig. The dynamometer, sensors, data acquisition system, enclosure, and all other support equipment are collectively referred to as the high-temperature linear alternator (HTLA) test rig.

The HTLA testing includes sweeping a range of temperatures, mover amplitudes, and electric loads to create a performance map of the

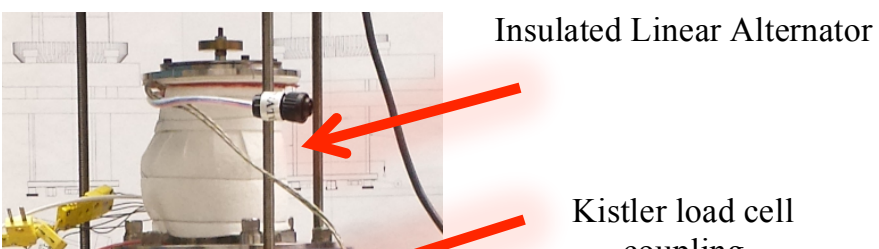
coupling

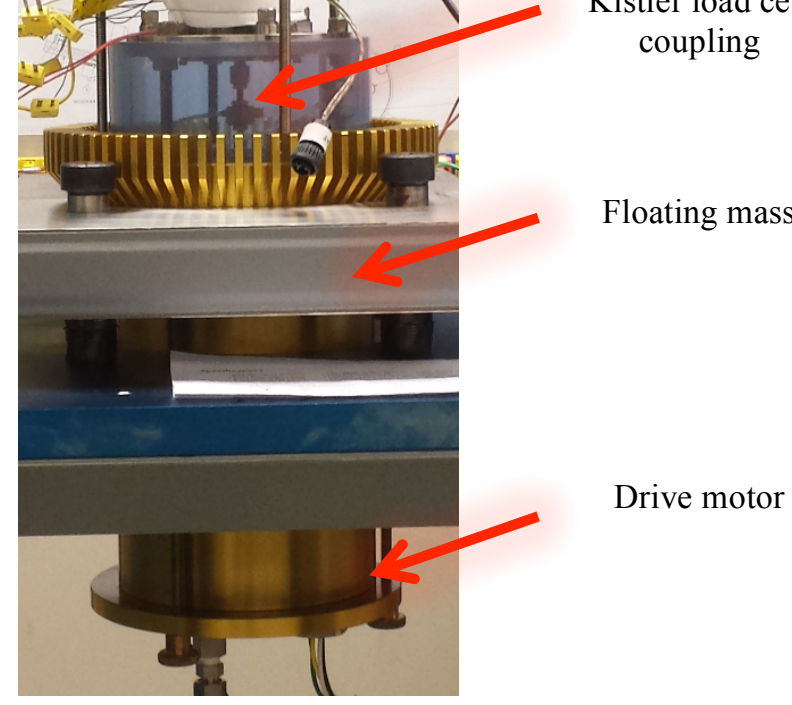

Figure 3. High-Temperature Linear Alternator Test Rig. alternator. The temperature will include $50,100,150,180$, and $200{ }^{\circ} \mathrm{C}$ using the heater bands. As part of checkout testing at some specified temperatures, the HTLA was tested to mover amplitudes of $2.5,3.5$, and $4.5 \mathrm{~mm}$ using electric loads set at $0.5,1.5$, and $2.5 \mathrm{Ohms}$. The HTLA terminal voltage, current, and power will be measured along with the applied force of the dynamometer taken from the load cell. This allows the mechanical work input, alternator efficiency, and power factor to be calculated. Testing is expected to complete later this summer.

\section{Improving Reliability or System Fault Tolerance}

\section{A. Backup Cooling via Variable Conductance Heat Pipe (VCHP)}

High-level project objectives for backup cooling include evaluating design improvements, identifying system integration challenges, and enabling tests in relevant environments. To enable passive thermal management of Stirling convertor hot-end temperatures during nominal and fault conditions, NASA GRC has been working with Advanced Cooling Technologies (ACT) to develop a variable conductance heat pipe (VCHP) to remove heat from the General Purpose Heat Source (GPHS) modules and maintain the integrity of the GPHS module, surrounding insulation, and Stirling convertor in the event that a convertor is turned off. Normally this cooling is provided by the Stirling convertor as it uses the thermodynamic cycle to accept heat source energy when in operation. However, there are scenarios when it would be desirable for the convertor to not be operating, such as during installation of the GPHS modules into the Stirling system or in the event of convertor failure. Obvious benefits of enabling backup cooling on a generator must be traded against the thermal and mass penalties, overall positive or negative impact on system reliability, and ease of integration. A Phase III Small Business Innovative Research (SBIR) contract was completed with ACT for the development of a VCHP, to minimize mass and conductive losses on a relevant configuration. The objective was to advance previous accomplishments from Phase I and II SBIRs, held with ACT, 
in order to mature the technical readiness level of the VCHP. In particular, this activity investigated optimization of the VCHP design by minimizing the mass and conductive losses, while also designing to interface with a Stirling convertor for system-level demonstration.

Figure 4 shows the bare ASC1HS Stirling convertor on the left and the test assembly with the insulation housing flange and VCHP installed on the right. This configuration uses the VCHP as the heat collector for the Stirling convertor and minimizes mass and conductive losses because it enables the VCHP to be more compact than other potential configurations. The insulation housing is not shown.

Beginning with a bare convertor, the coolant loops are installed into the copper cold-end flange and the bottom plate of the insulation housing

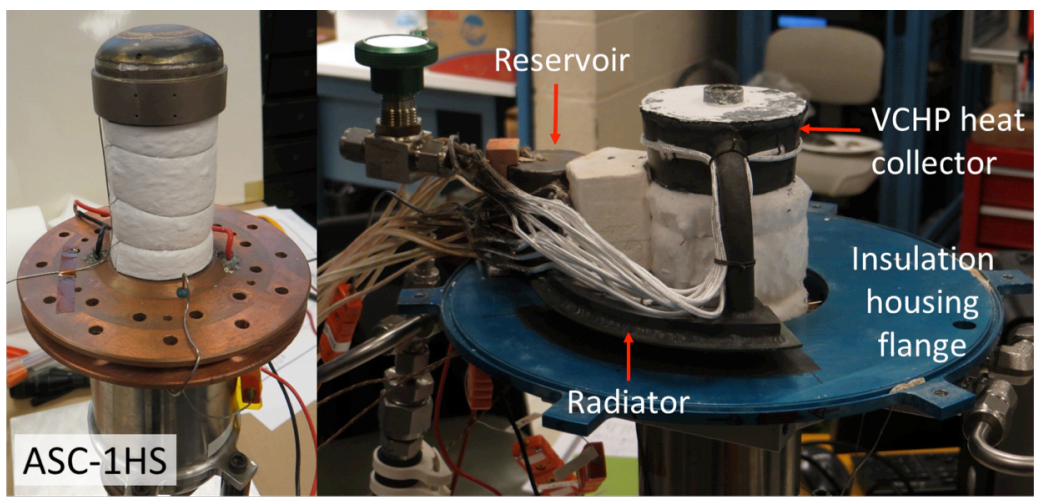

Figure 4. The ASC-1HS (left) integrated with the VCHP (right). is attached to the top surface of the copper flange with a layer of Tgon ${ }^{\mathrm{TM}}$ between the interface for improved heat transfer. Next, a layer of boron nitride paste was applied to inner diameter of the VCHP heat collector and on the outer diameter of the ASC-1HS heater head to provide improved heat transfer at that interface. The radiator or the VCHP was oriented to align with black paint on the insulation housing flange to improve radiation heat transfer. Boron nitride paste was also applied to the top of the VCHP heat collector and a nickel heater block containing electric heater cartridges was placed on top. Custom cut microporous insulation was packed around the test hardware hot surfaces and contained within a cylindrical aluminum housing. A spring-loaded preload mechanism, attached to the top of the aluminum housing, was used to hold the heater against the VCHP heat collector. This same build process was used for a second test where the VCHP was replaced with a solid nickel heat collector, and all voids from the heat pipe, radiator, and reservoir were filled with Kaowool insulation. Two data acquisition systems were used during this experiment. One was used to control convertor operation and heat input, while also monitoring and recording key convertor and VCHP temperature and power parameters. The second data acquisition system was provided by ACT to monitor and record data associated with the VCHP. The internal clocks on these systems were synchronized and some parameters shared for combining of data.

Testing was completed in two phases. The first utilizing the VCHP, and the second utilizing a solid nickel heat collector with the same external geometry as the VCHP, minus the heat pipe. Phase

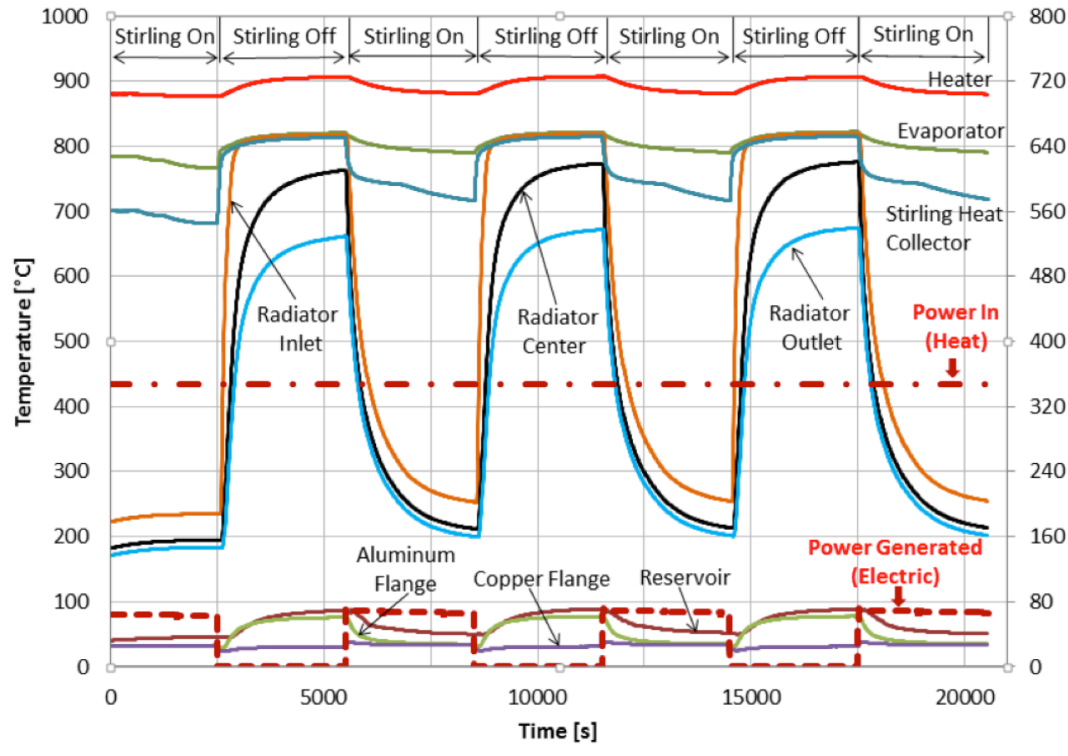

Figure 5. VCHP Demonstration Data. Data shows the VCHP prevented over heating of the convertor through successive start/stop cycles.

I began with a thermal loss test where the test article was heated to the operating temperature of $780{ }^{\circ} \mathrm{C}$ at the VCHP vapor temperature and $25{ }^{\circ} \mathrm{C}$ on the convertor cold end with neither the convertor operating nor the VCHP bypassing heat to the radiator. These temperature conditions were later matched during phase II with solid nickel heat collector, and the heater powers compared to experimentally determine additional thermal losses due to the VCHP to be approximately $5 \mathrm{~W}_{\text {th }}$. Next, the Stirling convertor was started and allowed to achieve steady state at a 
VCHP vapor temperature at $780{ }^{\circ} \mathrm{C}$ and the convertor cold end at $36{ }^{\circ} \mathrm{C}$. This test condition determined the heater power $(348 \mathrm{~W})$ to be maintained throughout the remainder of the test, as it would simulate the constant thermal output of a GPHS module. The VCHP was then successfully exercised through a total of four start/stop cycles, three of which are shown in Figure 5. The maximum convertor temperature stayed below $825{ }^{\circ} \mathrm{C}$, which matches the VCHP designed operating condition and is well below the Stirling convertor maximum temperature of $850{ }^{\circ} \mathrm{C}$.

The objectives of this Phase III SBIR, to develop and test a VCHP, to minimize thermal losses and mass, and to integrate with a Stirling convertor were all achieved. ACT developed, delivered, and completed a successful demonstration of the VCHP. The thermal impact of this VCHP design was experimentally demonstrated to be 5 $\mathrm{W}_{\text {th }}$, and steps were taken to minimize the mass by utilizing a more compact configuration and reducing the size of the VCHP heat collector. This work has improved upon the previous SBIRs by demonstrating for the first time a VCHP configured for heat rejection to the cold end of a convertor. Next steps for future VCHP development include testing in vacuum and a design configuration more representative of actual heat rejection in a generator.

\section{B. Vibration Reduction}

High-level project objectives include evaluation of system integration for mechanical design and control methods, characterizing performance of a single convertor against specified mission conditions, and demonstration of active vibration reduction to adequate levels when one convertor is turned off. To demonstrate those objectives for the ASC design, an active balancer is being pursued for evaluation at GRC. Sunpower Inc. will provide multiple balancer and controller units. Delivery is anticipated later this year, when the units will be evaluated for use in a future Kilopower test that utilizes a modified version of ASC-E2. One balancer unit will also be characterized on a single ASC against the reference ASRG specification, which required the ASRG to limit the peak dynamic disturbance force transmitted to the space vehicle to less than $35 \mathrm{~N}$ when both ASCs are operating. In this case, it will only be one convertor operating at specified operating conditions. Demonstration of active vibration reduction to adequate levels when one convertor is turned off is planned for next year, when additional funding and convertor assets become available.

\section{Reducing Mass and/or Size}

\section{A. Heat Rejection}

The development of heat rejection components are focused on mass reduction through improved performance and provide an alternative to sole source providers and/or costly components. The cold-side adapter flange (CSAF), shown in Figure 6, is a copper plate attached to the heat rejection zone of the ASC. The CSAF provides structural support for the convertor and provides a highly effective path to conduct heat from the Stirling cycle to the mounting features on the GHA. A two-phase heat pipe design, the Radial Core Heat Spreader (RCHS), has been developed as a direct replacement of the CSAF in the ASRG but could easily be applied to other generator architectures. The RCHS performance is comparable to that of the CSAF while the mass is $4 x$ times lower. It has been demonstrated in numerous relevant environments to characterize performance in vertical and horizontal orientations, including random vibration to simulate launch conditions and parabolic flights to simulate short periods of microgravity. The flat disk titanium water heat pipe is shown on right in Figure 6. The next demonstration in a relevant environment is

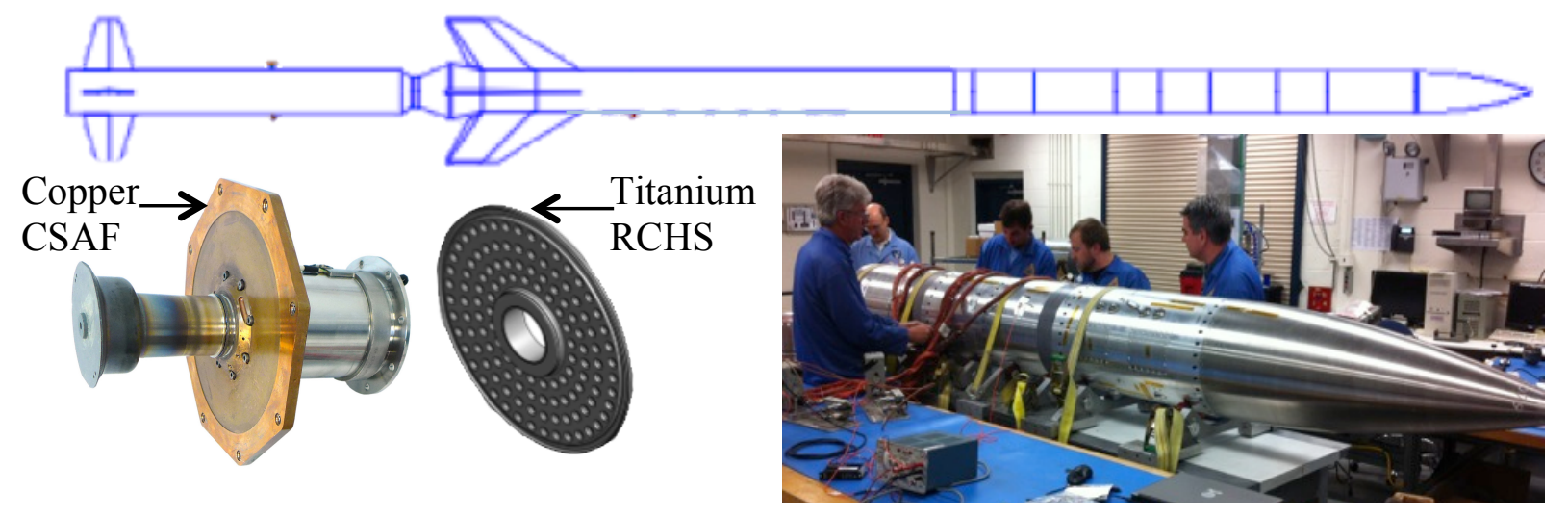

Figure 6. ASC's CSAF and RCHS.

Figure 7. Integration of RCHS test section into rocket. 
operation throughout a sounding rocket launch to demonstrate operation under relatively high random vibration loads and during six minutes in microgravity. The flight opportunity is on a Terrier MK70 Black Brant Mk1, a two-stage sounding rocket with a nominal altitude of $350 \mathrm{kM}$ and total flight time of 10 minutes. To prepare for launch this summer, GRC personnel have supported a variety of activity at Wallops Flight Facility (WFF), including payload verification testing, electrical checkouts, verification of GPS signal acquisition, acquisition of heat pipe telemetry before and after launch vibration testing, and payload integration. The payload section is shown in Figure 7.

\section{B. Insulation}

High-level objectives for insulation research include evaluation of insulation performance, comparison of materials and manufacturing methods, identify relevant mission environments, and identify system integration challenges. A Multi-Layer Insulation (MLI) was designed for high-temperature testing in vacuum with the ultimate goal of reducing size and mass of insulation packaging, compared to baseline designs. System analysis estimates suggest there is a potential mass savings on

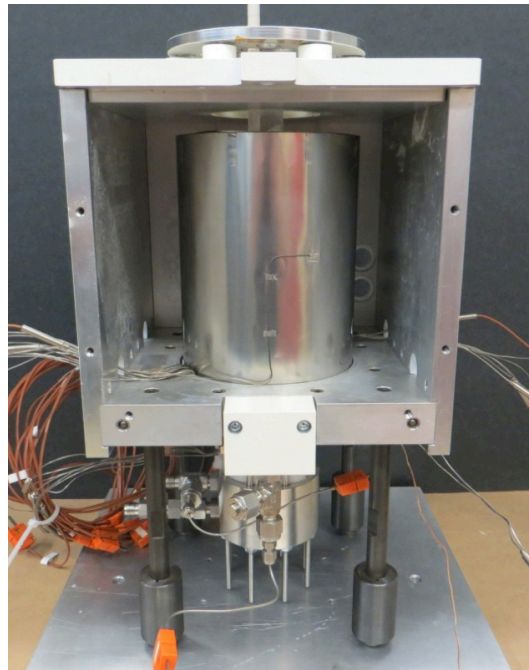

Figure 8. Test article with one side removed. Layer 25 shown. the order of $20 \%$ and potential to reduce the overall generator housing size. MLI is beneficial in environments where radiation is the primary form of heat transfer, such as the vacuum of space. MLI is composed of multiple layers of thin, low emissivity, radiation shields that are separated by thin, thermally transparent, separator layers which prevent direct contact between layers.

The MLI design has recently completed testing in GRC's vacuum Facility 17 (VF-17). Previous high temperature MLI testing at GRC employed circular flat radiation shields inside of a specially designed MLI testing chamber. ${ }^{6}$ However, that geometry was more general in shape and did identify integration challenges for Stirling convertor test hardware. For recent testing, MLI was designed to fit the geometry of an ASC housing, shown in Figure 8.

A thermal simulator, known as the Thermal Standard, was used to enable direct measurement of the heat energy being rejected to a simulated Stirling cycle. ${ }^{7}$ Materials used for the MLI in this test include stainless steel as radiation shield layers and Astroquartz as separator layers. Figure 8 shows the thermal standard installed into the ASC performance housing. One side panel of the housing has been removed to show the last stainless steel radiation shield. Coolant passages are used with a chilled water circulating bath to control the cold side temperature and to simulate the Stirling cycle.

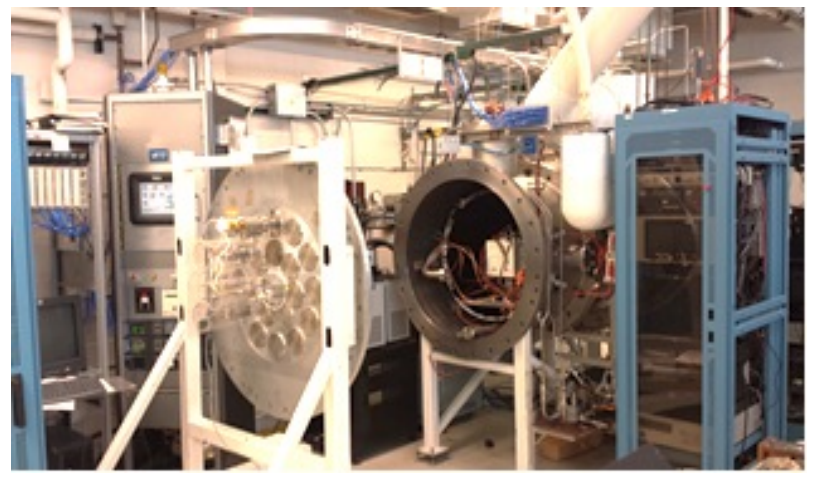

Figure 9. Test Article in VF 17. Test article in vacuum tank (white box in center).

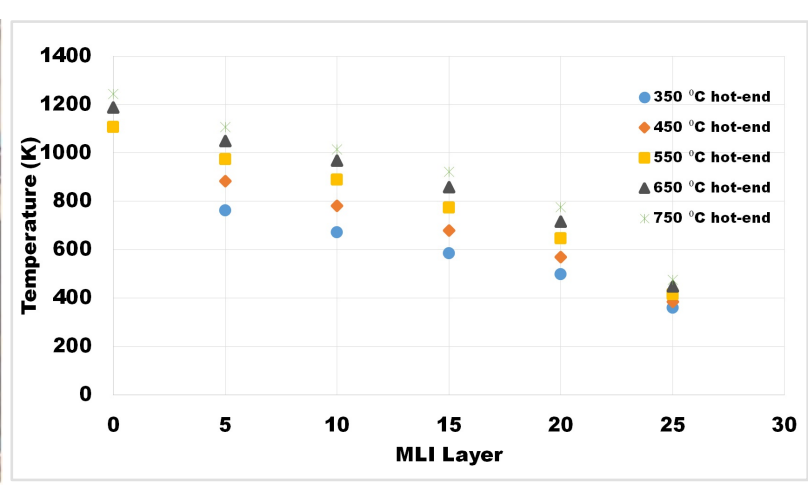

Figure 10. Radial Temperature Distribution in Foil Layers. Temperature profile through MLI layers.

Figure 9 shows the test article assembled in VF-17, along with the test support equipment. During this test, relevant temperatures, and other data was recorded using the standard Stirling Research Lab data acquisition system and test rack. ${ }^{8}$

After the test article was installed, VF-17 was allowed to pump down to below $5 \times 10^{-5}$ torr. For the test, data was gathered at 5 different operating points. At each of the operating points the cold side temperature was controlled to be $38{ }^{\circ} \mathrm{C}$, which is the low reject design point of an ASC during a space mission. The hot end temperature was 
increased in increments of $100{ }^{\circ} \mathrm{C}$ between $350{ }^{\circ} \mathrm{C}$ and $750{ }^{\circ} \mathrm{C}$. The $750{ }^{\circ} \mathrm{C}$ temperature point was chosen because it is similar to the hot-end design point of an ASC. Figure 10 shows the 5-minute average temperature data for each of the hot end temperature operating points. Layer 0 represents the heat source temperature, which is typically about $250{ }^{\circ} \mathrm{C}$ higher than the hot-end temperature. A thermocouple was installed every fifth layer to determine the heat transfer between the layers, and those temperatures are displayed in Figure 10. This data as well as the power required to maintain the different temperatures is being used to create a model that can be used to predict the performance of future designs of MLI for use on Stirling power systems.

Initial inspection of the data gathered during the MLI test shows a lower effective thermal conductivity, based on the published data for the baseline micro-porous insulation. The next stage of testing is to repeat the operating points used in the MLI test with baseline micro-porous insulation to better quantify the benefits of using MLI.

\section{Developing Advanced Concepts}

High-level project objectives are to develop advanced concepts for RPS designs for controller, convertor, and generator architectures to strengthen position as smart buyer, provide improved technical or cost options, or reduce the risk of single-sole provider. Recent activity in each of those areas is described below.

\section{A. Controllers}

The Single Convertor Controller (SCC) and Dual Convertor Controller (DCC) were designed by the Johns Hopkins University/Applied Physics Laboratory (JHU/APL) to actively control a single and pair of Advanced Stirling Convertors (ASC), respectively. The SCC was developed under the International Lunar Network program and has completed performance testing and over 12,000 hours of extended duration testing while controlling ASC-L at GRC. The Dual Convertor Controller (DCC), a version of the SCC, has successfully completed verification testing where it was connected to the RPS Systems Integration Lab (RSIL), a test environment designed to evaluate electrical interactions between a Stirling generator, electrical controller, power bus, and representative spacecraft electrical loads. Testing included operating a spacecraft bus in capacitive, battery, and supercapacitor configurations. The integration testing confirmed the DCC's ability to disconnect from the spacecraft when the bus voltage dipped below $22 \mathrm{~V}$ or exceeded $36 \mathrm{~V}$ while operating ASC-1 \#3 \& \#4 in the RSIL. The test effort demonstrated DCC control authority and fault tolerance while controlling ASC on a spacecraft bus and RSIL's ability to provide overall electrical power system testing and analysis. The short-circuit, overvoltage, under voltage and load step transients provided by RSIL were effectively managed by the ASCs and associated DCC controller both during single and dual input channel testing. ${ }^{9}$

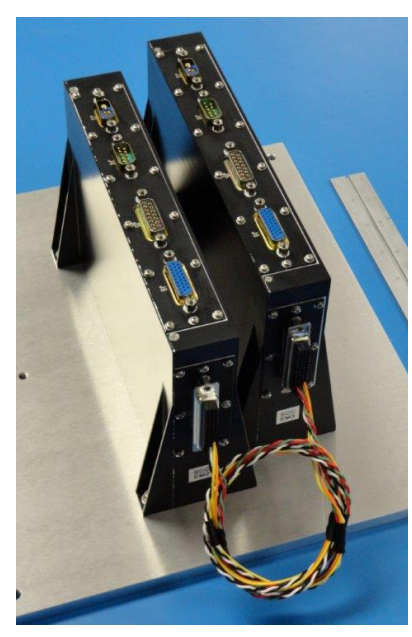

Figure 11. DCC shown.

\section{B. Convertors}

In support of a paper design for the modular generator design described in the next section, a convertor design is being considered. The convertor concept incorporates several lessons learned from past projects and new and novel features, which help simplify the assembly process, at least in theory. The 20 watt Stirling convertor is self-balanced by its double acting alternator moving masses, reducing vibration to the spacecraft without needing an active balancer and respective controller. Lower cost heater head options are also being considered for prototypical units to shorten the time for fabrication.

\section{Generators}

A generator paper design is being considered with the objective of increasing the reliability of a Stirling generator and providing a more fault-tolerant power system, compared to the ASRG architecture. This new generator, referred to the Modular Stirling Radioisotope Generator (MSRG), uses modular blocks to enable right sizing the power system based on mission needs. ${ }^{10}$ The modular blocks contain one General Purpose Heat Source (GPHS) surrounded by four Stirling convertors which are mounted to a heat rejection wall. The design considered one to eight modules, which provide 50 to 450 DC watts to the spacecraft, respectively. Number of required Stirling convertors and controller cards ranges from 4 to 32 . The convertors are balanced individually and are radiatively coupled to the GPHS modules to reduce the risk of creep on the heater head. Heat is rejected through the housing fins. 
The MSRG design, shown in Figure 12, was an attempt to address some of the lessons learned from the ASRG development, the NPAS study, and to address some of the concerns of spacecraft mission planners. Below is a list of features that attempted to build on the successful features and design of the ASRG while also adding features to enhance the generator robustness and reliability. The following features were desired in this new generator design:

1. Modular to enable scaling and high reliability

2. Shared heat source in single module

3. Radiative coupling between Stirling and heat source

4. Thermal insulation and hot-end materials are same as ASRG

5. Nominal heater head operating temperature of $760{ }^{\circ} \mathrm{C}$

6. Alternator temperature design limit of $200{ }^{\circ} \mathrm{C}$

7. Lower efficiency, more robust convertor considered

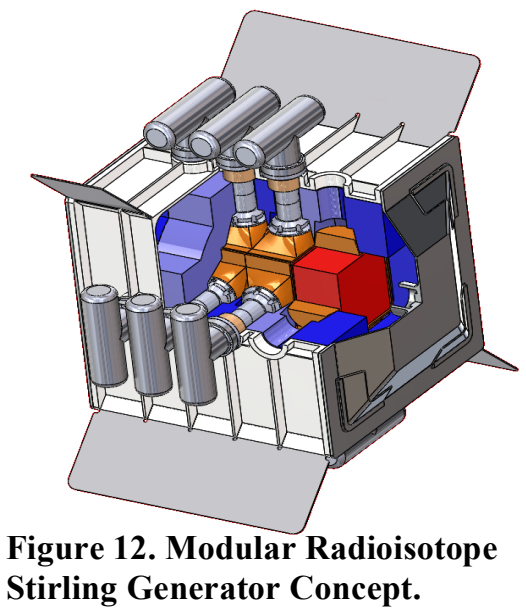

\section{Conclusion}

GRC's newly formulated Stirling Cycle Technology Development Project (SCTDP) continues development of Stirling based systems and subsystems, as well as development of maturing technologies by demonstration in higher fidelity systems and representative environments. Stirling Technology Research area tasks focus on a wide variety of objectives, including increasing performance and/or expanding mission space, reducing mass and/or size, improving reliability or system fault tolerance, and developing alternative designs. These high-level objectives guide the maturation of supporting technologies for infusion into future generator designs.

\section{Acknowledgments}

This work is funded through the NASA Science Mission Directorate and the Radioisotope Power Systems Program Office. Any opinions, findings, conclusions, or recommendations expressed in this article are those of the authors and do not necessarily reflect the views of NASA. The authors wish to acknowledge Gina Dugala, Steve Geng, Marc Gibson, Eugene Shin, Paul Schmitz, and Lee Mason for their commitments and contributions to Stirling Technology Research area.

\section{References}

${ }^{1}$ Schreiber, J.G., Thieme, L.G., "Final Results for the GRC Supporting Technology Development Project for the 110-Watt Stirling Radioisotope Generator (SRG110)", Proceedings of the 2007 Space Technology Applications International Forum (STAIF), Albuquerque, NM, February 2007.

${ }^{2}$ Wong, W.A., Wilson, K., Smith, E., Collins, J., "Pathfinding the Flight Advanced Stirling Convertor Design with the ASCE3", Proceedings of the Tenth International Energy Conversion Engineering Conference, American Institute for Aeronautics and Astronautics, Atlanta, GA, August 2012.

${ }^{3}$ Oriti, S.M., "Advanced Stirling Radioisotope Generator Engineering Unit 2 (ASRG EU2) Final Assembly", Proceedings from the Nuclear and Emerging Technologies for Space (NETS) 2015, Albuquerque, NM, 2015.

${ }^{4}$ Lewandowski, E.J. and Oriti, S.M., "Characterization of the Advanced Stirling Radioisotope Generator EU2," Proceedings of the Thirteenth International Energy Conversion Engineering Conference, AIAA, Orlando, FL, 2015.

${ }^{5}$ Wilson, S.D., Wong, W.A., "NASA Glenn Research Center Support of the Advanced Stirling Radioisotope Generator Project", NASA/TM-2015-218462.

${ }^{6}$ Cornell, P.A., Hurwitz, F.I., Ellis, D.L., and Schmitz, P.C., "Investigation of Insulation Materials for Future Radioisotope Power Systems (RPS)”, Proceedings from the 11th International Energy Conversion Engineering Conference, San Jose, CA, 2013.

${ }^{7}$ Briggs, M.H., and Schifer, N.A., ’Evaluation of Advanced Stirling Convertor Net Heat Input Correlation Methods Using a Thermal Standard", NASA/TM - 2012-217293 AIAA-2011-5578 March 2012.

${ }^{8}$ Oriti, S.M., "Extended Operation of Stirling Convertors at NASA Glenn Research Center," International Energy Conversion Engineering Conference, 2011-5726, Vol. 1, AIAA, San Diego, CA, 2011.

${ }^{9}$ Dugala, G.M., Taylor, L.M., et al., "Advanced Stirling Convertor Dual Convertor Controller Testing at NASA Glenn Research Center in the Radioisotope Power Systems System Integration Laboratory", Proceedings of the Thirteenth International Energy Conversion Engineering Conference, AIAA, Orlando, FL, 2015.

${ }^{10}$ Schmitz, P.C., Mason, L.S., Schifer, N.A., "Modular Stirling Radioisotope Generator", Proceedings of the Thirteenth International Energy Conversion Engineering Conference, AIAA, Orlando, FL, 2015. 